\title{
Attunement as a Pedagogical Starting
}

\section{Point}

\author{
Andrew Foran, PhD., St. Francis Xavier University, Canada \\ Email:aforan@stfx.ca \\ Evan Throop-Robinson, PhD., St. Francis Xavier University, Canada \\ Email:erobinso@stfx.ca \\ Kevin Redmond, PhD., St. Francis Xavier University, Canada \\ Email: kevinredmond8@gmail.com
}

\section{Abstract}

For many teachers, the value of pedagogical reflection is missing from practice. Rational educational approaches that prioritize judging and measuring students overshadow the relational dimension of teaching. Our study investigated this relational gap to explore more fully teachers' attunement to the child as a unique person. We examined lived experiences of six teachers pedagogically engaged with children $(\mathrm{K}-12)$ participating in an active outdoor living program. The program aimed to develop a youth network of friends, nurturing positive self-esteem and youth leadership. Using a phenomenological method, we facilitated open-ended interviews to show teachers' pedagogical awareness through hermeneutic conversations. We present the data as three anecdotes representing a synthesis of teacher reflection, writing, and on-going conversation. Our findings reveal the importance of being-in-time with children as teachers relate pedagogical moments with children learning outdoors. Through attunement as the flexibility to adapt educational challenges and approaches to suit the moment and uniqueness of the child, teachers became careful observers, allowing students to be children without the competing tensions of institutional expectations.

Keywords: pedagogy, phenomenology, outdoors, children, teachers

\section{Introduction}

What is the everyday teaching experience for teachers? Is going outside a part of that everydayness? In schools, the bells, desks, lesson plans, whiteboards, and student behavior, including classroom management, routines and procedures have become the quotidian in many teacherly reflections. Heidegger (2001) referred to such events for the teacher in "Dasein... absorbed in a particular, everyday world" (p. 206). Most often, the 
teacher is forced to make sense of the rapid encounters with children engaged in subject matter and measure outcome achievement as part of the learning process, while relating pedagogically to the child. How teachers consciously develop positive relations with students in the pedagogical context is central to this paper.

When the school day is paused, interrupted, or disturbed, there comes an opportunity for the child to be seen by the teacher (see Foran \& Saevi, 2012), and to be appreciated for their youthfulness. Our position in this paper is that childhood should not be judged; children need to be children, and teachers need to see the relationship once again as the starting point in their daily encounters. Even though institutional approaches to educating children have come to dominate how we see, hear, and even feel about our encounters with young people, we discovered in this study that teachers and their students, when engaged in outdoor activities, not only removed themselves from that daily operational institutional dominance, but also appreciated the relationality in education.

\section{The Study}

The Active Outdoor Living (AOL) study is based on an after-school program involving children and young people from Primary-Grade 12 from rural schools in northern Nova Scotia, who participated in outdoor activities twice a week throughout the 2016-2019 school years. In part, an aspect of AOL was to provide professional development to teachers, opportunities for them to learn about different types of outdoor activities that extended their indoor lessons, as part of their instructional practice. The study examined lived experiences of teachers pedagogically engaged with young people outside of school (see Foran, 2006), over repeated encounters throughout the school year. AOL provided outdoor experiences in Geocaching, environmental games, snowshoeing, Nordic skiing, hiking, canoeing, archery, and biking as conduits for teachers and their students to explore outdoor practices that encourage life-long activity, fostering wellbeing, a healthy-active self, and social connections, while embracing the natural world.

\section{The Teachers and Students}

This study examined the pedagogical awareness of six teachers committed to developing lessons that allowed for outside teaching and learning. These lessons, as part of the after-school program, were connected to regular lessons taught during the school day. The AOL aimed to develop a youth network of friends, nurturing positive selfesteem, and youth leadership. Normally, these youth would not have associated with one another during the regular school day. On average, AOL mentored 24 students per session after school.

The teachers involved believed the importance and value of just being with children was missing in their current teacher practice (see Foran et al., 2020). Exploring this relational gap also showed that pedagogical reflection (the relational dimension of being with children) versus technical reflection (the current technical-rational approach in teacher education) revealed a richer, more significant understanding of self and young people. Thus, pedagogical awareness seemed a vague concept to these teachers, and only formed a small part of everyday teacher reflections, easily lost at the expense of pressures 
associated with modern schooling. We questioned if this awareness is central to van Manen's (2012) pedagogical call: the adult responding to a child as a unique person, with the intention of leading them in an appropriate way at that particular moment in their life.

For these teachers, we sensed this awareness was evident when the encounter with children stirred something within them and they became aware of the pedagogical, as the relational element in teaching. This is a significant step towards realizing pedagogical awareness, but we discovered that attunement to the child was a critical starting point. This required a sensitive, relational knowing to capture teachers' lived experiences through fertile discussion that may lead many in education to deeper questioning when encountering children. We believe the inherent educational practices in teacher education should embrace a pedagogical orientation to counter the distorting effects of narrowly conceived educational methods, theories, and practices that often disconnect teachers from what is important in teaching - the relational. The AOL program allowed for teachers' attunement and the opportunity to see children in a different light as they shifted their teacherly reflections to the pedagogical.

\section{Attunement and Pedagogy}

Heidegger (2001) explained that to be attuned there must be a primary focus. For our discussion, this is the child. Heidegger furthered this relational attitude, asserting that despite distractions, stresses, and responsibilities, the adult can choose their focus, and "this can be interpreted...as 'attunement"' (p. 63) or lack thereof. Heidegger confirmed for us that the technical-rational model in education, the hyper fixation of instructional practice, the ever-present pressure of assessment, marking, and outcomes-based education results closes us off from the relational. Contemporary education's primary focus is myopic: achievement, ranking, metrics, comparators, and through a unifiedstandard curriculum, child growth is reduced to learning theories. Many teachers operating from this educational view are focused on their class and struggle within the pressures of teaching to see the uniqueness of each child, let alone attune themselves to pedagogical moments when they unfold.

\section{Homogenized Viewing}

The teaching world is absorbed by everydayness, a routine of predictability controlling the school agenda with competing tensions and pressures of standardization. The institution comes with inherent inequities that highlight power through policy, marking, testing, rules, and school-wide procedures. It is not much of a place for children, or an environment that allows a child to be a child (Biesta, 2012). Pedagogical attunement provides an entry point into understanding the relational elements in teaching: teachers becoming awake and aware of the depths and significance of pedagogy.

Attunement is essential for pedagogical practices to be even possible, and this was only the starting point for relational reflections in our AOL study. We learned from the teachers when they were engaged in outdoor activities with children and could distance themselves from the grips of contemporary classroom expectations. After the AOL sessions, it became apparent in conversations with teachers that they wanted to discuss 
the relational elements of their experiences, not the technical implications of lesson plans and instruction outdoors; however, this was not always easy.

These teachers, and many teachers in Canada, tend to default to a homogenized viewing of the teaching experience - the class as the living entity-reflections that focus on efficiencies of technical-instructional delivery and achievement/assessment rankings comparing classes as a whole. Merleau-Ponty (2010), in a reprinted classic from 1952, attested that this layer of institutional practice is a barrier because "children have not yet acquired equal footing in their relations with adults" (p. 374) and in such an environment how can they be recognized for who they are and want to be. What does this mean for children in the process of being and becoming their own person? Focusing our study was the nagging realization that many teachers may have lost the art of pedagogical practice due to pressures of modern instruction. Heidegger (2001) positioned environment as essential for relational connectivity - attunement, but how can we bring this pedagogical and reflective practice to the fore? Our realization in this study occurred when the teacher's practice was disrupted; the everyday school routine was suspended by being outdoors, accentuating pedagogical possibilities once again (Frieson \& Saevi, 2010; Saevi, 2012).

When do teachers know they are in a pedagogical moment and should not all moments with children be pedagogical? The teachers' responses to this question in our study revealed pedagogical understanding and reflection was not viewed as relational in practice or intent. These teachers, though well-meaning, dedicated, and focused professionals, saw their instructional delivery within the parameters of the overarching modern technical-rational school model that has come to dominate the importance of relational attunement. Even though as researchers we were witness to what is pedagogical, the teachers were not immediately seeing child encounters as pedagogical. The relational strengthening, or connections with students, through outdoor activities were the taken-for-granted aspects of their practices. We asked these teachers to reflect on the relational qualities of particular moments, using unspecialized language (Galvin \& Tordes, 2007), that was conspicuously absent from pedagogic thought and deliberation. At the root of our inquiry lies our struggle: how do we shift teacher reflections from a technical-rational orientation to be pedagogical? With attunement, the relational reflection becomes possible. Teachers sharing their lived experiences in our study were seeing, hearing, and feeling pedagogical significance in the moment, despite grasping at, or lacking the language to capture, their encounters with children and young people.

\section{Reflection and Attunement}

Merleau-Ponty (2010) affirmed the continuous need for pedagogical reflection that reveals adult views of a child. When asked about pedagogical reflection, teachers involved in AOL expressed a shared difficulty in finding words to express significant moments with students. Teachers claimed it was easier to discuss instructional aspects as part of classroom management and simpler to make sense of lesson plan delivery. However, these elements rarely capture the significance of the pedagogical relationship. van Manen (2012) presented a tradition of pedagogical reflection and practice that allows an adult to be in a moment of truth, knowing what is wanted without constraint. For teachers, this special way to reflect is a demonstration of a pedagogical attitude tactfully 
recognizing moments as significant encounters (see van Manen, 1991). Through AOL we realized that this special way of reflecting is becoming, or has become, a lost art with many North American teachers.

We asked the teachers engaged in this AOL study to participate in discussions that would introduce, or re-introduce, pedagogy as a relational practice. We practiced guided reflections with the teachers that focused only on the child, and we explored relational meanings versus what have become the traditional technical procedures and effective routines in lesson planning. Discussing children in this way prompted teachers to become attuned to children, reclaiming the relational in teaching, and recognizing the unique in each child when something beyond the outdoor lesson called to them as adults (see Foran \& Saevi, 2012; van Manen, 2012). Pedagogically, attunement not only acknowledges the child and the relationship with the teacher, but also embraces the mutual relationship that exists and deliberately fosters relationship with each child in our care (van Manen, 1991).

\section{The Paradox in Pedagogical Reflection}

Biesta (2012) claimed North America's attention is not focused on the pedagogical. Our research interests hopefully counter the current technical-rational dominance practiced in our schools. Exploring AOL teacher experiences offered richer understandings emanating from the interruption of everydayness even when encounters with young people occurred outside the school. We discovered that what teachers recalled in reflection often missed the pedagogical of the moment, the relational. Furthermore, teachers reached pedagogical realization only after continuous conversations exploring particular moments.

The value of our research efforts rest with relational experience that removes the relational commitment from the testing momentum created by schools (Biesta, 2010). Daily, teachers face a corporate model of education driven by standards that have diverted pedagogically reflective energy from relational to technical-rational practices (Biesta, 2012). From our research, thoughtful reflection on the relational trends towards the unconscious and serendipitous, highlighting the pedagogical paradox and importance of a more deliberate and conscious focus on the relational.

Despite traditional educational approaches there is a growing rebirth in the outdoor classroom (Foran, 2005, 2006; Foran \& Olson, 2008; Gill, 2010, Hubball \& Kennedy, 2009; Lieberman \& Hoody, 1998; Muebi et al., 2009; Mygind, 2007). AOL showed that outdoor experiences appear to positively influence and shape teachers and students. Environment does matter (see Heidegger, 2001) and, in the present context, student-teacher relational connections are more a serendipitous by-product of engagement than a conscious pedagogical focus. Exploring pedagogical opportunities surfaced anecdotes that revealed moments of attunement, and careful phenomenological conversations exploring lived experiences (van Manen, 1997) revealed pedagogical insight. The teachers found promise, despite the initial lack of attunement and difficulty in reflecting pedagogically, even as the outdoors increased their awareness of attitude in lived experiences with children.

Heidegger (2001) claimed attunement is realized only by being with othersbeing in their presence fully. Paradoxically, we ask: how is this possible in classes of 30- 
35 students or more as teachers balance all the competing teacherly priorities? Given the current climate of extensive online learning experiences for students and teachers brought about by pandemic conditions, we are more aware than ever of the impact on students of being fully present and witness movement toward even greater interest in outdoor experiences as an ongoing health-motivated strategy to mitigate virus transmission. van Manen (1991) reminded readers of a tactful expectation for teachers to be (fully there) for their pupils. As hard as that might be, or impossible in some instances, we believe van Manen is challenging educators to continuously try. This implies an ongoing attunement, and reattunement, to the relational with students. For van Manen, pedagogical reflection is continuous and not a simple one-time event; rather, it is a complex existential exploration of human encounters wrought with paradox and contradictions. AOL allowed us a starting point to explore attunement as a tactful way to orientate teacher reflections and reclaim pedagogical insights revealing deeper, richer teacher understandings of the relational bond often deemphasized in current teacher education programs in favour of more technical, cognitive, or behaviourist driven educational models (see Biesta, 2010, 2011, 2012). The anecdotes shared by the teachers in AOL explore encounters when attunement made it possible for pedagogical tact to come into focus rather than dismissed by institutional dominance. Our phenomenological conversations revealed that attunement allowed for the possibility of pedagogical reflection. The struggle was for the teachers to push beyond their reflections and re-enter the lived experiences from AOL with pedagogical tact (van Manen, 1991, 1997) — to deliberately acknowledge and focus on student-teacher relational awareness.

\section{A Phenomenological Orientation}

In using a phenomenological method, we show rather than argue what was present or absent in the teachers' pedagogical experiences. The lived experience always has its own quality, and the sense may be pre-cognitive and ever so vaguely felt. According to Heidegger (1962), one might experience that what looks like "nothing" still might be "something" (p. 173). The AOL study was designed to disrupt the everyday teaching, allow an outside place to strip away institutional barriers for attunement to be possible, have teachers reflectively write lived experience descriptions (van Manen, 1997) capturing what might seem to be "nothing," and explore the "something," acknowledging the pedagogical complexities. In follow-up discussions with teachers, we explored these complexities as part of the hermeneutic conversations to reveal pedagogy as something essential in a teachers' practice.

Acknowledging the uniqueness of teachers' experiences, we allowed for open conversations to explore their lived experiences and remained true to the phenomena of attunement and hermeneutic pedagogical reflection. We investigated phenomenologically the outside teaching experience using open-ended interview questions to burrow into the reflections, isolating what teachers determined as pedagogical. Through this recognizable textual data and hermeneutic analysis of the lived experience (see Foran, 2006, p. 44), the routineness of pedagogical student-teacher relations, as taken-for-granted, may be interrupted and enlightened by their ability to recall the ordinary experience (Denscombe, 2007), peel away the superficial layers, and reveal the profound. With phenomenology, the moment must be explored for the root experience to surface, making apparent the 
essence of the experience and, in our context, understanding what it means to dwell pedagogically in a place.

Central to this discussion is the experience of teachers leading students, and specific to their reflections drawing on a pedagogical attitude: drawing out, going beyond the act of instruction, moving deeper into their understanding of attunement, and connecting relationally to the uniqueness of each student. This relational effort is deeper and more profound than assessment marks, lesson plans, and reports that tend to dominate a teacher's time and practice. The teachers in our study claimed that current curricular initiatives nullify relational possibilities with tasks that are mere platitudes and teacher rhetoric justifying a teacher's efforts and time in claiming the paramount importance of the child. These teachers stated educational policies, educational law, school rules, school procedures, and curriculum coverage, including assessment pressures to rank student achievement, obscured the relational bond and diminished the specialness of the relational between teachers and their students.

\section{Lived Experience Descriptions}

Our intention is to explore teachers' lived experience (van Manen, 1997), the concrete moment of the teacher engaging children in learning, but outside the conventional classroom. The crafting of anecdotes, written by teachers through reflective conversations, provides the data to support our study. The anecdote is a portrayal of a concrete lived experience; it attempts to guard against "abstract theoretical thought" (van Manen, 1997, p. 119), essential for pedagogical reflection. Through these anecdotes, we present pedagogical moments outside the classroom and each anecdotal description is based on actual experiences of teachers with young people. This provided us an intimate link to past moments, but also, with hermeneutical reflection, revealed elements needed to inform pedagogical practices.

The focus on the lived experiences of teachers in outside places provided anecdotes where the nothing could be analyzed for the something regarding the taken-forgranted in relational encounters. Through follow up, open-ended, and phenomenologicalhermeneutic conversations with these teachers, pedagogical insights involving attunement and reflection emerged. The anecdotes in this article represent a careful blend of teacher reflections, writing, and on-going conversations about children involved in AOL.

\section{The Complexities in Pedagogical Reflections}

Pedagogy is a living experience, reserved for a teacher's reflection, in living through a child's moment. However, the teacher must be attuned to the child and recognize the moment and the uniqueness of the child. There is an energetic layer at play here for educators who spend time alongside young people and children: the consciousness of these moments. For teachers, living in the moment with children should be nothing but pedagogical. However, to fully grasp the moment, we position the need to continuously reflect pedagogically on our encounters with young people (Merleau-Ponty, 2010). 


\section{You Could Just Feel It!}

Attunement is the entry point for the teacher into the student's world, in a way, to be truly present. Being attuned, and reflecting pedagogically, allows for convergence of two thoughts: recognizing there is a young person with unique sensibilities and that adults need to eventually reflect on these moments to make sense of them pedagogically. Teachers need to become awake to their responsibility in their dealings with young people. The notion of becoming awake or aware of the pedagogical was realized when Jenna commented during an AOL session that, "you could just feel it." We became curious as to what was felt? Was this attunement, the intuitive response to the call of pedagogy (van Manen, 2012) for a teacher? Jenna furthered this feeling with what she was experiencing at that moment, playfulness:

School is not about play, it's learning and marks, procedures and policies, and sometimes it's very hard to see children in this world. When we went outside, I realized I was able to see different things for my students but only if I let go and follow their lead. AOL gave us an opportunity to play together, to be active, and to enjoy life. No better way to be active than in the outdoors, a place I feel many kids do not see, or know much about. This moment of realization truly came when I observed students running from their last learning station and I could see they were into this! And so was I and this surprised me: the afternoon provided my students and me an opportunity to have real time to play and they took advantage by participating fully, but it was me hesitating - I felt like the kid at the edge of the playground wanting to join, but not knowing how. So, I watched, and I saw students engage in the activity and I sensed this was good; I could just feel it. The students moved as an intertwined blob of youth: dancing, singing, laughing, giggling, piggybacking, running, jostling, and utterly free from this world and this would never be allowed in school. I think I started to connect to this group because of their courage. These young people being able to break the hold trapping them as some institutional drone; no longer caught up in an adult's world of busy! And it's funny. I see this as so great for the students because it was an opportunity to learn outside, but really this was an opportunity for them to grow in an open environment where they could play and live in their imaginations with no hesitant thoughts, you know all those adult restrictions. I believe the most important thing in teachers' and students' lives is to ensure we allow time and space for play. I know play should not be judged as childish! And play needs to be more than the scheduled 15 minutes at the sound of some recess bell.

We applied the lens of attunement to Jenna's lived experience to reveal a deeper pedagogical understanding. Letting go for Jenna meant the normative learning expectations that at times confine teachers to the technical aspect of teaching and reflecting were trumping the relational possibilities. Connecting with children, for Jenna, was realizing the courage these young people demonstrated in showing who they are in a state of play, regardless of the adult and their peers' watchful gaze. Being in a state of 
play can allow for other possibilities if we recognize the moment and allow the moment to be the encounter. Jenna experienced a moment when teachers can break the institutionalized hold, resisting the ordinary of teaching and attune themselves, being an adult fully there for the child pedagogically.

How was Jenna attuned to these young people; this is a world of adult busy, where the child is an institutional drone - not a place of childhood wonder or play, let alone growth as a person through their own imaginations? Or was it just a question of being outdoors interrupting the taken-for-granted, and allowing for other relational possibilities? Jenna allowed the children to be growing children, offering the opportunity to make and follow through on their directions of engagement outdoors.

When children are permitted to act freely, they can do so without the constraints of adult thinking and expectations; thus, as Heidegger (2001) stated: "one must, as it were, stand back and let the other human being be.... Attunement...contains the relationship toward the way and the manner of being able to be addressed and of the claim of being" (p. 211). As a pedagogical moment, there is a significant difference between directing the students to do an activity and being engaged with the students in an environment that encourages self exploration-expression, student input, and group choice. Such moments are not always predictable or possible to manufacture, they require awareness to the moment, intuition, and openness to diverse contexts (indoors and out). Jenna was attuned to the students, standing back, letting them be, as they made their own decision to play. "Pedagogy if it's pedagogy, should not define, and should prevent defining a child's life in relation to other people, adults in their lives, and institutions" (Merleau-Ponty, 2010, pp. 377-378); otherwise, children will begin to see a destiny determined for them. Through this experience, outside the conventional classroom, students chose and actualized their choice - an experience as important to their personal growth and maturation as times tables are foundational to mathematical progression or being a child is to becoming an adult. Such experiences become potential principal points of reference propelling future decision-making processes and activities - all a part of becoming an adult if we allow them to be children.

If Jenna was not attuned, we hazard the opportunity to see students in the moment would have been missed; thus, the experience may have resulted in returning to a classroom approach - a nonevent. As educators, allowing students to make real choices outdoors makes for rich personal social group experiences which, when actualized through appropriate pedagogical tact and reflection, facilitates healthy student-teacher relations. During a follow-up conversation, Jenna was questioned to explore another possibility: were all children engaged? There was a deliberate pause before her answer: I am not entirely sure? I know it was a fantastic moment, the energy was there, and for teachers this is key. You know the end game is about getting students involved, but no, I am not sure if this was an equal experience for all my students.

When reflecting on the moment, Jenna was asked to visualize this class to see each student. She said, "I admit there were a couple of students, and there always will be, that were quiet. And I am sure they still enjoyed the free play session!"

Thus, a paradox and a key realization emerged for us: a class experience does not mean equally experienced by all- the homogenized North American view. As Jenna stated: 
Teaching today is about numbers and how to play the numbers game: We only have so much time to make a plan work, and in that time, connect to the students, so the effort is always connected to as many students, most of the time. However, in that effort of providing the best experience possible for a class, it is easy to lose sight of the one or two.

Therein lies the complexity: creating a positive experience for a class. Teachers work within the reality of large class size and can genuinely interact with a few of the students at a given moment. Being attuned may not be enough. It is a critical starting point, but pedagogical reflection requires teachers to see each student, even those on the "edge of the playground" and open up their practices to pedagogical reflection.

The follow up conversation was designed to question the need for children to be seen in a moment as children, recognizing that a teacher needs to see more than the class to manage as they tackle an activity. When this was repositioned for Jenna, there was agreement and struggle: "How do I see them all? The system is flawed and that's why I like taking them outside. Because it's there they get to come into their own.” The pedagogical effort here is to see into the experience and recognize what this moment could mean for each child and to question that understanding specifically. Being attuned in that moment for Jenna meant feeling the childish energy and connecting to a moment of choice to follow their lead. But pedagogically, through reflection, Jenna realized that she did not really see what was happening for she too was swept up in the type of moment teachers want to create for their students, albeit what she would consider to be just play for the class. Pedagogy does not ask us to not plan for these moments, but to examine them relationally so that we see each child as engaged human beings.

\section{Seeing Children}

While the exhausted students were recovering from their first activity of the afternoon, David gave his students the option to either move onto a new activity or to repeat. To his surprise, and "without hesitation, the entire group responded, enthusiastically, that they wanted to repeat the Olympic challenge." David later stated: "I was shocked, as I thought the students were exhausted and had enough, and I was sure this part of the lesson on "Games Around the World" was going to flop! These kids are too old for this type of game." David's account shows how reflection, when childfocused, can provide an awakening of adult perceptions on a moment shared with young people:

Waiting at the bottom of the snow-covered hill, the prisms of fluffy snowflakes glistened amongst the countless smiles greeting me at the start of the second challenge. When I saw all the glowing faces, heard the laughter and their jokes, cheers and taunts, I was flush, my cold feet and ears were no longer cold, and that tired feeling from hours of lesson planning did not matter. I was standing at the finish line watching the students collect themselves from the team snowshoe-sled relays. Most of the class were still panting, lying, or kneeling in the snow, holding onto the webbing, some still sitting on the purple sleds, all runny noses, rosy cheeks, and red ears. The teams moved back towards the start line, and I actually saw what was happening: despite the differences in athletic abilities with the peer 
groups, they were excited to try again with their teams to cross the finish line. But this wasn't about winning. I am unsure if it was the friendly competition, the novelty of the activity, the beautiful sun-filled day or the students' openness, their attitudes, but they were having a great time - at this moment, this was their Olympics! Whether the students knew it or not they were experiencing what I miss from my childhood, and what they may come to miss later as adults. They were enjoying the outdoors, letting themselves be kids in the moment, releasing their minds from everything. Right at that moment, I connected to somethingmy judgement of them - and my misinformed views. I realized I never really saw them as children in my school.

The primal euphoria of children engaged in winter activities outdoors as a source of adult envy and reflection is tenable in the anecdote above. Although the child often perceives the teacher as the authoritative expert, there is still much that teachers can learn in the presence of children. As Merleau-Ponty (2010) explained, "the child and adult reflect each other like two mirrors endlessly placed face to face. The child that we believe exists is the reflection we desire" (p. 70). Through the students' exhaustion, hilarity, and positive open attitude, David happened upon his own personal realization that, as an adult he was missing the youthful exuberance manifested by his students. His role as observer and personal reflections reveal deep pedagogical engagement-recognizing childhood as special and distinct and different from being an adult — and respecting the fragility of this engagement.

In our follow up conversations, David realized this was a moment when young people could not be treated like adults in the school. David realized his planning of the moment was concerned around weather; it would "flop" because of maturity, or "provide the exercise benefits required to be healthy," not what this experience could mean for any one of his students. Yet "it is impossible for the teacher to separate observation from action [and the] connection between educator and child is not an accessory; it is essential in the situation" (Merleau-Ponty, 2010, p. 69). Merleau-Ponty (2010) furthered the pedagogical distinction with the following: "Intervention should only be understood through the child's reaction. Therefore, the adult simultaneously learns to understand...self and learns about the child. [It is in] our relationships with children, children become what we make of them" (p. 69). This reciprocal pedagogical relationship is further exemplified when the exhausted students choose to repeat the same activity, rather than move to a new one. The students were not concerned with the teacher's time planning the task or finishing the plan as intended. The students' desire to repeat the physically draining activity surprised David and highlights Merleau-Ponty's "connection between educator and child," which reflects a relationship where children's contributions are sought out and actively engaged; they are guided to an experience and not robbed of being who they are in a moment.

The outdoors allowed for something else, a realization that the participation and commitment demonstrated to David resulted in a lesson that was not a "flop." On the contrary, the lesson was a success from the planning perspective of post-lesson reflection. David acknowledged and recognized the benefits of going outdoors with his class, and he became attuned to realizing that he needed to let them be who they are in a moment. It 
was in the moment of his surprise that the group wanted to do the activity again that he came to realize the pedagogical.

When the pedagogical lens is focused on David's lived experience description, the complexity of childhood, and what it means to understand this stage of life is revealed to educators. In a follow up discussion with David, entering into this AOL moment, we wanted to first understand when attunement was possible. David's response was when he recognized that the class was doing this without him: "The teams moved back towards the start line" and this was happening without adult/teacher guidance. This movement reflected the wishes and direction of the child in control of their experience. David explained that as far as teaching goes, no teacher could have asked for anything better: students motived and self-directed: "I really disappeared, I was invisible to them."

David's pedagogical practice in creating the space for the child underpins such emerging opportunities and the resultant being in the moment noted above. Heidegger (2001) solidified this, explaining "It is being-with that means a way of existing with you in the manner of being-in-the-world, especially a being-with [Mitsein] one another in our relatedness" (p. 112). As David reflected, being in that moment opens a space for students to enjoy that child-centered euphoric state. His willingness to engage student input suggests a child-centered approach through which he as teacher benefited pedagogically, learning how to be aware from his students, while also unconsciously fostering relationships. Merleau-Ponty (2010) explained the nature of this relationship: "We cannot easily exclude our adult presence when observing the child's behavior. When witnessing the relation between adult and child, rather than solely focusing on the child's own nature, we should describe the child's relationship with the adult" (p. 373). Recognizing and fostering this relationship through attunement, Heidegger (2001) stated: Attunement is not something standing for itself but belongs to being-in-the-world as being addressed by things. Attunement and being related [Bezogensein] are one and the same. Each new attunement is always only a reattunement...of the attunement always already unfolding in each comportment. (p. 203)

Hence, as educators, we should be in a continual state of reattunement with students and aware of our pedagogical reflections.

David's follow up conversation exemplifies reattunement: "I knew then that I did not really know any one of these children. I know that! I know what I had in my childhood, but these kids, no. They show up at my school and I teach them-simple." We think as teachers and as adults; we try to understand the child in front of us in terms of our own childhoods, and as a result, we sometimes make judgements about the younger generations that may not be accurate or fair. This pedagogical realization allowed David to grasp his struggle with relating to children: "they are not like me, and I was not anything like them as a child."

In our efforts to teach, we tend at times, to normalize children based on what we think a child should be, and this is not often possible because the child before us is unique and distinct in their own identity. David furthered this understanding with the following: "When I was a kid, I was all about winning, and I thought, if I could ramp up this activity - even though I thought it would flop - that the competition would get me through the afternoon. I was wrong." David realized that the pupils in his school, and for the most part, in his classes, were not unmotivated, noncommittal. They repeated the activity, "not for the sake of winning," but because "they wanted to experience it once 
again as afterschool friends." They were not like him, he came to understand, but what he realized, was that he spent too much of his relational time judging them as a group.

That afternoon outdoors, away from his school-based judgements and student bias, afforded David an opportunity to connect to the possibility of his own pedagogical shortcoming. Despite a fantastic afternoon with full participation, David came to understand that he did not know the students, and his past efforts were not about really getting to know who they are as people; rather, he knew them simply as a plan, a group to manage, and students to be challenged. This moment brought David to a place where his pedagogical intentions were in question.

The follow up conversation revealed to David the need to "get to know each child" for who they are at the moment, and "that is the starting point for my future encounters." David also realized that the confines of school life can mask the pedagogical possibilities because school as structured resorts to normalizing actions and behaviours in our efforts in North America to deliver a "curriculum of sameness" (Carson \& Johnston, 2001) for our students. Despite our own limitations and differences, attunement precipitates opportunity for insight through connections and diversity, visible and invisible. Pedagogically, David grasped the want to know this child, in this moment and allowed that to be his starting point when being with children.

\section{Frantic}

Kylie recalled the countless hours setting a simple handheld global positioning unit (GPS) for an activity called Geocaching, a lesson that included high school student peer mentors. Kylie remembered the high school students echoing her very concerns, "I sure hope we did this right!" Kylie assigned each high school student their own AOL group and provided reminders on operating the GPS, and their clues for helping find each of the hidden caches. Kylie recalled the following:

Once the kids experienced their first successful find, I backed off, and let the groups head out on their own, searching for the remaining caches. At one point, every group was out hunting caches, all the kids were exploring, and I had a chance to really step back: I saw kids running and trekking across the school grounds, these kids were all in. All I could think was wow! I was not expecting this, I was so caught up in my lesson, I was frantic with the technical and logistical details of the GPS units, I never even thought how this was going to play out for my students. This level of thinking never crossed my mind. Every group filed back to home-base, with jumbled letters that needed decoding. The students from both age groups were on hands and knees working the letters, trying to figure out and to decode the message. There was no reward, no prize, no recognition to be won, and no mark, no measure to success, really? I am not sure this was what connected me: success. But I know I was super aware of their engagement - that could not be missed — but I also felt distant. I was there, yes, but I was not "with them." I was not a part of their experience. And yes, sure the lesson was a success - the hidden caches containing the letters were foundoutcome reached! And it was a great feeling to see 16-year-old students alongside the younger children of 12 and 13 doing the activity. There was a real connection among them all and this hit home when they were sharing a moment with one 
another. I think this is what acceptance looks like, what it's supposed to look like for children. And then they started clapping - clapping!

The context of traditional lesson planning is an adult perspective, a technical-rational approach focused on attainment of learning outcomes. Yet, "children are not...'miniature adults'...the child's consciousness is not identical to the adult's....The child possesses another kind of equilibrium than the adult kind" (Merleau-Ponty, 2010, p. 131). Kylie was afraid the lesson would be derailed due to the technology and the complex structure of the activity, yet the children, oblivious to such rational concerns, and through the liberty of being outdoors in an environment of shared autonomy within the activity, revealed Merleau-Ponty's (2010) "child's consciousness as a positive phenomenon" ( $p$. 131).

Eliciting the lifeworld of the child is highly relational. As teachers, our pedagogical tact influences when a child opens up and flourishes in the moment or closes up and withers. "Only the efforts of a phenomenological reflection can take up others and what I witness...of others... [and] phenomenology ...can show how the essences appear in the casual unfolding of a life" (Merleau-Ponty, 2010, pp. 325-326). In this instance, Kylie acknowledged and encouraged the child's exceptional lifeworld contributions as uniquely phenomenological - there was an experienced "connected-ness" and "distanceness" that may offer insight into how Kylie was attuned to a moment with young people. We contend such a pedagogical attitude, as revealed by Merleau-Ponty and for Kylie, should be the primary focus in planning and practice.

Kylie's attunement is demonstrated as she relinquished her technical-rational preconceptions to reflect on dynamics of those engaged in the activity. It was not the GPS technical details that enhanced the relational in the activity. It was the personal efforts combined in a cooperative environment - people being with one another, focused on each other, attuned to one another at that very moment. Kylie realized she was fully aware in this moment when students of different ages were connecting to one another completing the word scramble. When Kylie was questioned on her meaning of connecting, she stated: "the older students were doing more for the younger kids in this program than I was doing for them... an example of mentoring that should have been conscious to me, I am the adult leading the growth of these students." This was a difficult realization for Kylie, but her ability to attune herself to what was unfolding allowed her to realize that there were dimensions to her teaching practice that needed to be called into question - the meaning of the pedagogical.

When discussing the anecdote with Kylie, we raised the part of her preoccupation with the students' level of engagement and the realization of sharing at the end. Kylie made an important realization pedagogically:

I am always focused on getting it right, I never really am able to seize the opportunity to just be with the students-like those high school students did. I am focused on the wrong things. Success was the number of finds and how many could scramble the clue.

We discussed this focus and Kylie determined that the pressure of outcome achievement becomes what teachers see, and its hard to let go of that: "You make the plan and you 
achieve the outcomes - that's why we are teachers." However, the moment she was attuned to the class, she realized that she was dealing with people, not a paper document, the curriculum, or a checklist of outcomes to reach and assess. The children were not simple coordinates to plug into a GPS. They were people and this was demonstrated in group - a spontaneous eruption - a celebration:

I thought they were clapping for me, talk about arrogance! My students were clapping for the high school students; they are the ones who were really there for them, and the high school students were clapping for middle school group: They shared the moment, they made the connections. I counted outcomes.

Kylie realized a pedagogical need to recognize students as people, with expectations and unique vulnerabilities no different that those that she harbors for herself, not mere participants in a program or in the classroom. With this realization, Kylie has come to accept a limit in her practice that these are young people with a life beyond school and AOL, and if she is to be a meaningful part of this, she needs to begin questioning why she wants to be engaged with young people in and out of school. As she explained, "When I reflect about being able to go outdoors with children this is really about me being able to become "unschooled'."

With deliberate focus and attunement to the child, for both the student and the teacher, "the sheer joy of successfully managing one's embodied dimension is hugely rewarding... Progress and achievement are available to all, at every level. The development of self-confidence and self-respect are palpable in such lessons" (Whitehead, 2005, p. 16). Pedagogical attunement allows for each child to become on their own personal level and, as in the anecdote above, without standing out in a group but being an integral member of the group and their accomplishments. We tend to forget how important it is for children to find their way with others in acceptance.

The pedagogical in a teachers' practice asks the educator to consider why they even want to be with children in the first place (Mollenhauer, 1983), that is, the entry point into the lives of young people. A curricular outcome, and the achievement of the outcome, despite the dominance this may have in a teacher's life, is only one factor in the reason why we teach. Kylie's pedagogical reflections revealed the outcome, or getting the lesson perfect, was not what made the moment significant; rather, it was the relational exchange between people, giving of oneself freely to each other as was modeled by the youths.

Heidegger (2001) argued that we must "remain properly attuned to the subject" and through a common language, "reflect on those meanings" devoid of scientism (p. 141), where the relational supersedes the technical and the rational. The outdoor classroom is a natural fit, offering students and educator a disruption in the educational everydayness routine. Here, Kylie, once attuned, stood back allowing the students freedom to reveal themselves to one another and connect at a most basic level. She experienced the moment as frantic on the planning front, yet a primordial pedagogical connection was realized within a group.

Taking lessons outside does not guarantee the noted disposition of pedagogyjust as positive student-teacher connectedness and relations can never be imposed by a teacher upon students. Kylie demonstrated the possibilities of attunement when teachers let go of their egos in fostering positive student-teacher relations. This effort of realizing 
the adult/teacher is just another person within the engagement is deserving of our respect and consideration. Students and teachers recognizing each other as equals for their unique insights and contributions enhances respect, engagement, and relationships. As MerleauPonty (1968) explained, "The child understands well beyond what he knows how to say, responds well beyond what he could define, and this after all is as true of the adult" (p. 13). Attunement for Kylie was a humbling moment that brought into question her intentions of why she wanted to be with young people and what role she should or could have if she reflects tactfully on her planed and unplanned engagements. In this way, our teaching life and dwelling within pedagogy can allow the child to be seen (Foran \& Saevi, 2012), and unfold as they grow. For Heidegger (2001) "this is a temporal unfolding.... a coming to presence" (p. 3) that we as educators are fortunate, to contribute to and learn from.

\section{Attunement and Pedagogical Reflection: A Basis for Tact}

As we attempted to see attunement, and the efforts required to move teacher reflections on their lived experience descriptions from the program to the pedagogical, Jenna revealed the homogenized hold gripping teachers. Gill (2010) noted that as educators, "it means having a clarity of vision about the kind of learning opportunities that children and young people deserve, and about the challenges they are capable of taking on - and succeeding at - if only we give them the chance" (p. 22). This means creating life challenges, struggles and successes, where students can respond in their own way to these life moments and glimpse more of who they are becoming because of the experience. Attunement includes the flexibility to adapt challenges and approaches to suit the moment and uniqueness of the children; affording students such opportunities are pedagogical moments. Heidegger (2001) prompted readers to think that there is a pedagogical time, a "dwelling with the child... a suspended moment;" for Heidegger this dwelling is "wesan (dwelling) and Wesan (essence): a temporal unfolding, of a coming to presence" (p. 3). This is a moment when Jenna allowed the students to be seen (Foran \& Saevi, 2012), their essence valued, and dwelling in the moment, a reflection of being-intime with young people.

Jenna's awareness of the moment was revealed in her witnessing the act of play with young people. When she attuned herself to the event, she became a careful observer of young people. In doing so, she recognized their need to laugh, dance, sing, and live imaginatively - without inhibition - a usual constraint among adults. Pedagogically, she was able to remove herself and go deeper into her observation of an "intertwined blob of youth." This is the overly generalized view teachers in North America may take when thinking about classes and the students in their schools - a mass of people. Jenna took time in the moment to see more, to look for the "nothing" and was able to see Clair as "something," a student withdrawn in school, and a young woman who could not envision, let alone imagine a future. Jenna said:

I am so glad I volunteered to be in the AOL program. Every session has allowed me to make some type of connection to a student - Clair for example. In school, I have never seen her act this way; I would not think it possible. In the hallways and classrooms, she is despondent, but out here she becomes, she grows, she can really hit her stride. 
After Jenna offered this student connection, she commented that this would not have occurred during the regular school day because there are too many things "getting in the way." Jenna clarified the barriers with the notion that schools were never meant to be institutions and that somewhere along the way we lost sight of what we are really supposed to be doing with young people. Within the blob of youth, Jenna watched a young person enjoy a moment and could see that maybe, "just maybe Clair can find her way" and that she herself as the teacher needs to start seeing this "promise" as Clair's possibility. Jenna's pedagogical reflection clearly demonstrates the relational dimension that has become lost on teachers resulting in institutionalized experiences.

Teachers, as parental people, are in privileged positions, adored and respected by children, a cardinal point in the lives of students, holding the position of role model when this relationship is positive. David signifies "in every civilization children are for the parents an image of their own childhood, and the parents are for their children an image of their own future" (Merleau-Ponty, 2010, p. 311). What we pedagogues emulate today is what today's children bring to future generations. Do these teachers manifest what educators should aspire towards for today's youth and those in the future? The cooperation, camaraderie, effort, enthusiasm, learning, and primal pleasure in being active outdoors we see as pedagogical, attunement, and renewal of pedagogical reflection. As Kylie demonstrated, the adult is present, but they are not the constant central focus of the child. And paradoxically, sometimes it is best to let other youth serve as mentors. Yet this requires a letting go of the adult ego.

Being conscious that many of the students we teach will or will not supersede our academic achievements, while other students will or will not demonstrate skills and societal contributions that are positive, highlights the importance of recognizing the value of student contributions regardless, for they are all learning to become persons. Despite students' youthfulness, they hold insights that are not only personally valuable but may also be meaningful to us as teachers and/or our students. Fostering such a climate of endorsement underpins the realization that we teachers cannot be everything to everyone, but it is essential that we are something to each student in our care. This begins with [re]attunement and meaningful pedagogical tact and knowing the child in our care. As in the case of Kylie, "it means having a clarity of vision...that children and young people deserve... if only we give them the chance" (Gill, 2010, p. 22). If we give students the learning opportunities they deserve, while maintaining a conscious student-teacher connection focus, the pedagogical can exist without judgments.

Kylie, David, and Jenna show an attitude that they want to live as teachers and be present to young people as an adult in their lives. Comparatively, these teachers allowed the students to be themselves (Heidegger, 2001) — children to be children (Biesta, 2012) — without the competing tensions of current institutional expectations. They were conscious of making an active choice in the moment. All continued being watchful of the group (van Manen, 1991), monitoring the pulse of the class, their well-being, and through their teacherly participation supported at a respectful distance what they were observing. Attunement in this example is an opportunity whereby the students and teacher engage in an activity and fully see the potential. As Merleau-Ponty (2010) furthered, "We are all indissolubly tied to the fact that the other is facing us the way we are facing him" (p. 70). Extending the study on phenomenological seeing (Foran \& Saevi, 2012), being attuned to 
the moment facilitates seeing. Attending to the phenomena as experienced by each child, $d$ welling alongside them in their world is the portico to attunement and cultivating rationality with the child and allowing them to be seen.

Merleau-Ponty (2010) noted that: "institutionalized children have the feeling of being at the margin of adult life, and the secrets that surround them are troublesome" ( $p$. 299). The AOL study highlights the importance of disrupting the current everydayness of educational routine, making conscious the focus on relational attunement in our pedagogical planning and practice. It is entering into the child's lifeworld where, as pedagogues, we feel before we understand, we allow the child to be seen before we see. This is about attunement with the student as the foundation of pedagogy in practice and not just a happenstance, serendipitous by-product of a well-planned technical rational routine.

Merleau-Ponty (2010) was clear: the child "must, as much as possible, be in contact with a living situation" (p. 124). Thus, our error here may be perpetuated in our so-called reflections when we fall, as educators, into the trap of the adult error: the child is viewed as the undeveloped adult in terms of intellectual development, physical maturation, and social sophistication. We must not see the child's world in this way: "the child's drawing is not an adult drawing that lacks something... it is not a reflection of the world. The child's drawing is a manner of expressing his experience of the world" (Merleau-Ponty, 2010, p. 241). Pedagogical reflection and tact are essential to the child's willingness to reveal or express their views in the world. "Husserl's conception of reflection as a sense-giving, as an opening onto an unreflective realm" (Merleau-Ponty, 2010 , p. 335) is the pedagogue's portico to the child's lifeworld and Heidegger's beingwith facilitates relational attunement.

\section{Disruption}

Pedagogical attunement is coming to sit alongside the child, breaking the homogenized view of mistaking the class to be the child by acknowledging the lifeworld of the child. Pedagogical reflecting is an example of nurturing relational practice and the pedagogues' tact is essential to these encounters with young people. Paramount in the pedagogical relationship is the consistency and reliability of the several abilities that tactful teachers may or may not have: to see a certain way, to hear a certain way, and to respond in a certain way for each child (van Manen, 1991). Our pedagogical practice should be attuned to children whereby "we stand back and let the other human being be" (Heidegger, 2001, p. 211). Children should not see their destiny determined for them. This is not a relationship without boundaries, but certainly complex with paradox. Merleau-Ponty (2010) cautioned readers to consider that "without realizing it, the [parent/caregiver] passes between a wish that the child will be strong and free and a wish that [the child] will always be dependent on [them]" (p. 80). We explore pedagogical possibilities - to see a future for the child: "Many conflicts are born from parents envisioning the future. Children and adolescents think only of the present. Neither one can behave otherwise. Therefore, no equality is possible between the parent and the child" (Merleau-Ponty, 2010, p. 80). Further to Merleau-Ponty's point: "We cannot avoid encroaching upon the child's freedom [other than] to what is strictly necessary: not to respect all the child's fantasies, but also not to consider everything a fantasy" (p. 83). 
It is within this construct that pedagogical attunement and tact is framed, as where relationships are determined by the ability of teachers to "enter into the world of a child" with thoughtfulness and tact (van Manen, 2002, p. 3), accepting the paradox of relational complexity. On entering the child's world, we see "as a central point of hermeneutical procedure that one is never supposed to have the last word" (Gadamer \& Grondin, 2006, p. 91). Here we envision that within an attuned pedagogical practice, it is the student who reveals the last word, even if only for that moment, suspended, underpinning the relational possibilities for them to flourish.

\section{References}

Bachelard, G. (1994). The poetics of space. Beacon Press. (Original work published 1954 in French).

Biesta, G. J. J. (2010). Good education in an age of measurement. Ethics, politics, democracy. Paradigm.

Biesta, G. J. J. (2011). Disciplines and theory in the academic study of education: A comparative analysis of the Anglo-American and Continental construction of the field. Pedagogy, Culture and Society, 19(2), 175-192.

Biesta, G. J. J. (2012). Giving teaching back to education: Responding to the disappearance of the teacher. Phenomenology \& Practice, 6(2), 35-49.

Denscombe, M. (2007). The good research guide for small-scale social research projects (3rd ed.). Open University Press.

Carson, T., \& Johnston I. (2001). Cultural difference and teacher identity formation: The need for a pedagogy of compassion. JPCS, 6(2), 259-264.

Foran, A. (2005). The experience of pedagogical intensity in outdoor education. Journal of Experiential Education, 28(2), 147-163.

Foran, A. (2006). Teaching outside the school: A phenomenological inquiry [Unpublished doctoral dissertation]. University of Alberta.

Foran, A., \& Olson, M. (2008). Seeking pedagogical places. Phenomenology \& Practice, 2(1), 24-48.

Foran, A., \& Saevi, T. (2012). Seeing pedagogically, telling phenomenologically: Addressing the profound complexity of education. Phenomenology \& Practice, $6(2), 50-64$. 
Foran, A., Stewart Stanec, A., \& Mwebi, B. M. (2009). Active outdoor living: Let's get out of the gym! Canadian Association Health, Physical Education, Recreation, and Dance Journal, 75(1).

Foran, A., Robinson, D. B., Munroe, E., Thurber, T., \& Eilifsen, M. (2020). Pedagogy: A teachers' practice. Phenomenology \& Practice Special Issue: Being and Becoming a Teacher, 14(1), 39-56.

Friesen, N., \& Saevi, T. (2010). Reviving forgotten connections in North American teacher education: Klaus Mollenhauer and the pedagogical relation. Journal of Curriculum Studies, 42(1), 123-147.

Gadamer, H-G., \& Grondin, J. (2006) Looking back with Gadamer over his writings and their effective history: A dialogue with Jean Grondin (1996). Theory Culture Society, 23(85). doi:10.1177/0263276406063230

Galvin, K., \& Todres, L. (2007). The creativity of 'unspecialization:' A contemplative direction for integrative scholarly practice. Phenomenology \& Practice, 1(1), 3146.

Gill, T. (2010). Nothing ventured... Balancing risks and benefits in the outdoors. English Outdoor Council. http://www.englishoutdoorcouncil.org/wpcontent/uploads/Nothing-Ventured.pdf

Heidegger, M. (1962). Being and time. Harper \& Row. (Original work published 1926 in German).

Heidegger, M. (2001). Zollikon seminars. Northwestern University Press.

Hubball, H. T., \& Kennedy, J. (2009). Context-based learning: Research and practice implications in outdoor experiential education. Transformative Dialogues, 3(2), $1-19$.

Lieberman, G., \& Hoody, L. (1998). Executive summary: Closing the achievement gap: Using the environment as an integrating context for learning. State Education and Environment Roundtable. Science Wizards. http://www.seer.org/extras/execsum.pdf

Merleau-Ponty, M. (1968). The visible and the invisible. Northwestern University Press.

Merleau-Ponty, M. (2002). Phenomenology of perception. Routledge \& Kegan Paul.

Merleau-Ponty. M. (2010). Child psychology and pedagogy: The Sorbonne lectures 1949-1952. Northwestern University Press. 
Mollenhauer, K. (1983). Vergessene Zusammenhänge. Über Kultur und Erziehung. Juventa.

Mygind, E. (2007). A comparison between children's physical activity levels at school and learning in an outdoor environment. Journal of Adventure Education, 7(2), $161-176$.

Saevi, T. (2012). Why Mollenhauer matters. A response to Klaus Mollenhauer's book Forgotten Connections: On Culture and Upbringing. Phenomenology \& Practice, $6(2), 180-191$.

Saevi, T., \& Husevag, H. (2009). The child seen as the same or the other? The significance of the social convention to the pedagogical relation. Paideusis, 18(2), $29-41$.

van Manen, M. (1991). The tact of teaching: The meaning of pedagogical thoughtfulness. State University of New York Press.

van Manen, M. (1997). Researching lived experience human science for an action sensitive pedagogy (2nd ed.). Althouse Press.

van Manen, M. (1999). The pathic of pedagogical practice. In P. Kansanen (Ed.), Discussions on educational issues (Iss.8, pp. 75-97). University of Helsinki Press, Department of Teacher Education.

van Manen, M. (2002). The tone of teaching. Althouse Press.

van Manen, M. (2006). Reflectivity and the pedagogical moment: The practical-ethical nature of pedagogical thinking and acting. In I. Westbury, \& G. Milburn (Eds.), Making curriculum strange (pp. 49-78). Routledge.

van Manen, M. (2007). Phenomenology of practice. Phenomenology \& Practice, 1(1), $11-30$.

van Manen, M. (2012). The call of pedagogy as the call of contact. Phenomenology \& Practice, 6(2), 8-34.

Whitehead, M. E. (2005) Physical Literacy. A developing concept. Unpublished paper presented at the British Philosophy of Sport Conference 2005, Stanley, England. 